\title{
XPS STUDY ON THE EFFECT OF LOW-ENERGY ELECTRON IRRADIATION ON DNA DAMAGE BY $\mathrm{Fe}^{3+} \mathrm{ION}$
}

\author{
Hyung-Ah Noh ${ }^{*}$, Yeun-Soo Park ${ }^{\dagger}$ and Hyuck Cho* \\ *Physics Department, Chungnam National University, Daejeon 305-764 Korea \\ ${ }^{\dagger}$ National Fusion Research Institute, Osikdo-dong, Gunsan, 573-540, Korea \\ Received April 16, 2015 / 1st Revised June 18, 2015 / Accepted for Publication June 19, 2015
}

We have employed X-ray photoelectron spectroscopy (XPS) technique to examine the combined effects of low-energy electron (LEE) irradiation and $\mathrm{Fe}^{3+}$ ion on DNA damage. pBR322 plasmid DNA extracted from E. coli ER2420 was used for preparing DNA-Fe ${ }^{3+}$ sample. The C1s XPS spectra were scanned for LEE-irradiated and LEE-unirradiated samples and then curve-fitted. For the samples with LEE irradiation only or with Fe ion only, no significant changes from pure DNA samples were observed - a single effect of either $\mathrm{Fe}^{3+}$ ion or LEE irradiation did not cause a significant damage. However, when these two components were combined, the DNA damage was increased quite significantly, compared to the sum of DNA damages caused by $\mathrm{Fe}^{3+}$ ion and by LEE irradiation independently. This observation is consistent with our previous results [Radiat. Res. 177, 775 (2012)] which was done using gel-electrophoresis technique. Partial interpretation of the observed spectrum peaks was also attempted.

Keywords: DNA damage, XPS, Electron beam, Dissociative electron attachment

\section{INTRODUCTION}

After the Sanche group in Canada reported that lowenergy electrons (LEEs) with sub-ionization energy of DNA interact with DNA and cause the structural and chemical changes in year 2000 [1,2], it is now well established that low-energy electrons (LEEs) can cause DNA damages such as single-strand break (SSB), double-strand break (DSB), base lesion, and cross-links between bases by ionization and excitation processes [1-5]. LEEs with a specific energy resonantly attach to a constituent of DNA and forms a temporary negative ion, followed by dissociation of the parent molecules, causing a bond break at a specific site of the DNA this process is called dissociative electron attachment (DEA) $[4,6,7]$. When high energy $(\mathrm{keV} \sim \mathrm{MeV})$ radiations interact with biomolecules, they produce secondary species such as radicals, ions and LEEs through the local energy deposition to the targets. Among these

Corresponding author : Hyuck Cho, hcho@cnu.ac.kr

Physics Department, Chungnam National University, Daejeon 305-764, Korea secondary species, LEEs below $20 \mathrm{eV}$ are the most abundant $\left(\sim 5 \times 10^{4}\right.$ electrons/MeV) and important species because they can indirectly generate DNA damages [1,2]. Most of LEEs in this energy region do not have energies enough to directly ionize DNA molecules [4], but they can subsequently react with DNAs and their subunits and lead to various DNA damages indirectly $[1,5]$. Therefore, the understanding of the interactions of LEEs with DNA subunits is important in understanding the indirect DNA damages.

Following this initial study, there have been many investigations on LEE interactions with the simple DNA components like nucleobase, deoxyribose analogues, and phosphate analogues as well as the more complex targets like oligomer and plasmid DNA [8-15]. However, in a real complex cellular environment, DNA is surrounded by many other molecules such as proteins and metal ions as well as $\mathrm{H}_{2} \mathrm{O}$ and interacted with these surrounding molecules chemically in vivo [16]. It is, therefore, necessary to consider the effects of surrounding molecules connected to DNA or DNA subunits when studying DNA damages induced 
by LEEs or high energy irradiation. Motivated by this situation, we have previously studied the combined effects of LEE irradiation and $\mathrm{Fe}^{3+}$ ion on DNA damage [17]. Metal ions are important catalysts for oxidative damaging reactions in DNA and other biomolecules [18-22]. Fe ion bound with DNA components will affect the sensitivity of electron capture for the incoming LEE and, consequently, the yield of DNA damage will be changed. In our previous study, the multilayered DNA-Fe ${ }^{3+}$ films were prepared by lyophilization technique and irradiated by 3 or $5 \mathrm{eV}$ electrons. After LEE irradiations, the irradiated DNA-Fe ${ }^{3+}$ films were recovered and analyzed by electrophoresis to identify DNA damages. For quantifying the SSB and DSB, the gel electrophoresis technique has been commonly used, as were in the experiments by the Sanche group [1]. However, with electrophoresis, we cannot tell which bonds of DNA are broken and what kind of fragments are produced from the damages. Therefore, the gel electrophoresis technique has a limit in probing the DNA damage mechanism in detail. To better understand the damage processes, various different techniques have to be developed. In this report, X-ray photoelectron spectroscopy (XPS) was used for analyzing the bond cleavage in DNA+Fe films with and without LEE irradiation to study the combined effects of LEE irradiation and $\mathrm{Fe}^{3+}$ ion on DNA damage.

\section{MATERIALS AND METHODS}

For DNA sample, pBR322 plasmid DNA extracted from E. coli ER2420 was purchased from New England BioLabs Inc. It is a double-stranded and supercoiled DNA with 4,361 bp (base-pair) in length and $2.83 \times 10^{6}$ daltons in weight. Ferric chloride $\left(\mathrm{FeCl}_{3}\right)$ was purchased from Sigma-Aldrich Chemical Co. and $\mathrm{FeCl}_{3}$ solution was prepared immediately prior to use. All other reagents and solvents were purchased from Sigma-Aldrich Chemical Co. and used as received without further purification. Tantalum (Ta) foil for DNA film base was purchased from Goodfellow Cambridge Limited.

A home-made lyophilizer was used to prepare dried DNA films on Ta foil. The details of the lyophilizer were described elsewhere [17]. To treat plasmid DNA and $\mathrm{FeCl}_{3}$, we used nanopure water (distilled and deionized water $\left(18.2 \mathrm{M} \Omega . \mathrm{cm}, 25^{\circ} \mathrm{C}\right.$; $\left.\left.\mathrm{ddH}_{2} \mathrm{O}\right)\right)$. We prepared pBR322 DNA solution, mixed with TE (Tris-HCl $10 \mathrm{mM}$, EDTA $1 \mathrm{mM}, \mathrm{pH} 8.0$ ) buffer to dilute to a concentration of $0.05 \mu \mathrm{g} / \mu \mathrm{l}$, and $\mathrm{FeCl}_{3}$ solutions, mixed with the same TE buffer to make a con- centration of $6 \mathrm{mM}$. The prepared pBR322 DNA solution and $\mathrm{FeCl}_{3}$ solutions were mixed in a $0.5 \mathrm{ml} \mathrm{mi-}$ crocentrifuge tube to make DNA- $\mathrm{Fe}^{3+}$ complex. DNA-Fe ${ }^{3+}$ mixture solution of a volume of $9 \mu \mathrm{l}$ was carefully dropped on a clean Ta foil and was spread on the Ta foil to a circular shape with around 5-mm diameter. In the lyophilizer, DNA-Fe ${ }^{3+}$ solutions became frozen and water molecules in the solutions were extracted by the cryogenic sorption pump. Finally, we obtained dried DNA-Fe ${ }^{3+}$ films with about 5 monolayers (ML) on the Ta foils. For each run of the experiments, eight DNA-Fe ${ }^{3+}$ films were prepared and loaded into the vacuum chamber for LEE irradiation. The electron gun generated a uniform electron beam over the entire sample surface on the sample holder. Each DNA film was irradiated individually with constant irradiation time, beam current, and incident electron energy. Under this condition, the electron energy and the irradiation time were $5 \mathrm{eV}$, which is below the ionization threshold of DNA, and $5 \mathrm{~min}$, respectively, giving a total exposure of approximately $1.81 \times 10^{14}$ electrons per DNA film. The irradiation of DNA film was carried out under ultra-high vacuum (UHV) condition, $\sim 10^{-10}$ torr, pumped by a turbo molecular pump. The pure DNA films having no $\mathrm{Fe}$ ion was made following the same procedure.

Both un-irradiated and irradiated DNA- $\mathrm{Fe}^{3+}$ samples were analyzed using Thermo Multilab2000 XPS system at the Center for Research Facility, Chungnam National University. This system was equipped with a $\mathrm{Mg} / \mathrm{Al}$ dual anode beam source, a concentric hemispherical analyzer, and a channeltron detector. The $\mathrm{Mg}$ $\mathrm{K} \alpha$ source was used for the experiment, and the power and the base pressure were maintained at $150 \mathrm{~W}$ and $4 \times 10^{-10}$ torr, respectively. The angle of incidence of the $\mathrm{X}$-ray beam with the sample normal was about $42^{\circ}$ and the analyzer was positioned normal to the target surface. XPS spectra were recorded in the fixed analyzer transmission mode with energy steps of $0.1 \mathrm{eV}$. From XPS spectra, we could determine the binding energy of the electron ejected from an atom which was bonded to other atoms. When an atom makes a bond with other atoms, its valence electrons are involved in the bonding and their electronic states are changed, which subsequently affect the binding energies of the core electrons. Therefore, a carbon atom, for example, could have different $\mathrm{C} 1 \mathrm{~s}$ binding energies depending on what kind of bonding it makes with what kind of atoms. This energy shift in the binding energy is called the chemical shift. By exploiting this chemical shift, we could tell that from what kind of chemical bonding the detected electron came from [23]. And, by examin- 


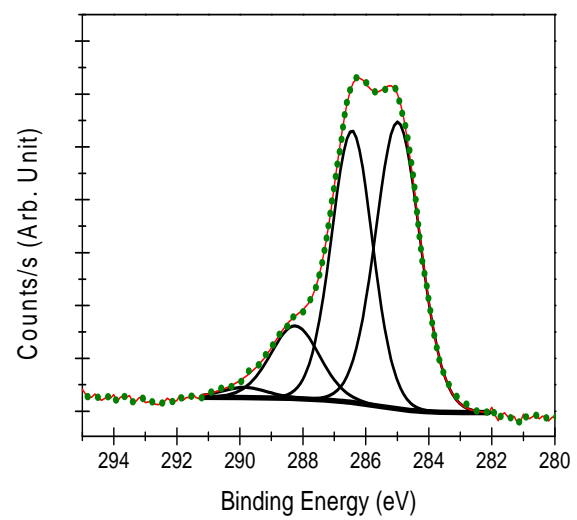

(a)

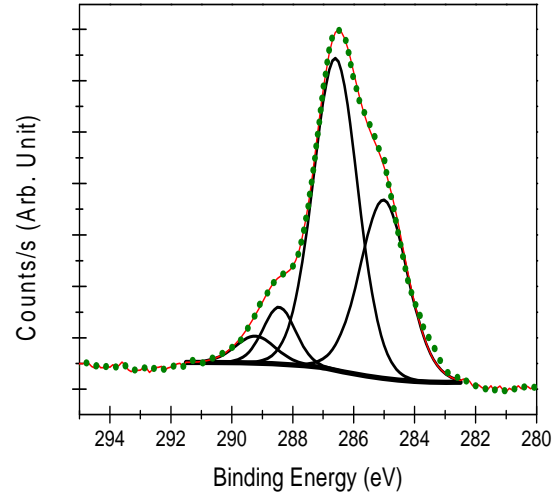

(b)

Fig. 1. XPS spectra of $\mathrm{C} 1 \mathrm{~s}$ region for DNA-Fe ${ }^{3+}$ film samples : (a) DNA without electron beam irradiation and with no Fe ion, (b) DNA-Fe ion with electron beam irradiation. Dots indicate the raw spectra, narrow lines the curve-fitted peaks, and thick line at the bottom the backgrounds.

Table 1. Binding Energy of $\mathrm{C}$ bond and relative sizes of each bond peak without and with "electron irradiation - $\mathrm{Fe}$ ion".

\begin{tabular}{ccccc}
\hline \multirow{2}{*}{ Peak number } & Bond type & $\begin{array}{c}\text { Center } \\
\text { Binding energy } \\
\mathbf{( e V )}\end{array}$ & 285 & \multicolumn{2}{c}{\begin{tabular}{c} 
Relative size of each constituent peak (\%) \\
\cline { 3 - 4 }
\end{tabular}} & & $\begin{array}{c}\text { without (electron irradiation- } \\
\text { Fe ion) }\end{array}$ & $\begin{array}{c}\text { with (electron irradiation- } \\
\text { Fe ion) }\end{array}$ \\
\hline 1 & $\mathrm{C}-\mathrm{H}, \mathrm{C}-\mathrm{C}$ & 45.7 & 33.5 \\
2 & $\mathrm{C}-\mathrm{N}, \mathrm{N}-\mathrm{C}-\mathrm{N}$ & 39.9 & 54.9 \\
3 & $\mathrm{C}-\mathrm{O}-\mathrm{C}, \mathrm{C}-\mathrm{OH}$ & $286-287$ & 12.7 & 7.3 \\
4 & $\mathrm{~N}-\mathrm{C}=\mathrm{O}$ & 288 & 1.7 & 4.3 \\
\hline
\end{tabular}

ing the changes in the XPS spectra between the 'un-irradiated' and the 5-eV 'electron-irradiated' DNA-Fe ${ }^{3+}$ samples, we could suggest possible bond cleavages in the samples.

\section{RESULTS AND DISCUSSION}

DNA consists of the bases, sugar and phosphate and has numerous bonds consisting of atoms like $\mathrm{H}, \mathrm{C}, \mathrm{N}$, $\mathrm{O}$ and $\mathrm{P}$, and therefore XPS spectrum for each of these elements can be recorded. Among these elements, more detailed C1s spectra were scanned for the following two different groups of the samples: (1) DNA with neither electron irradiation nor $\mathrm{Fe}$ ion, and (2) DNA with both electron irradiation and $\mathrm{Fe}$ ion. The spectra are shown in Figure 1.

As pointed out previously, a carbon atom could have different $\mathrm{C} 1 \mathrm{~s}$ binding energies depending on what kind of bonding it makes with what kind of atoms, and it means that, for a single $\mathrm{C} 1 \mathrm{~s}$ spectrum, there could be several different contributions from the ejected photoelectrons with slightly different binding energies de- pending on different bonding of the carbon atom. Typical bonding of carbon atom are hydrocarbon bonds $[\mathrm{C}-\mathrm{H}, \mathrm{C}-\mathrm{C}]$, carbon bonds to nitrogen $[\mathrm{C}-\mathrm{N}$, $\mathrm{N}-\mathrm{C}-\mathrm{N}]$, bonds with oxygen atom [C-O-C, C-OH], amide bond $[\mathrm{N}-\mathrm{C}=\mathrm{O}]$, urea bond $[\mathrm{N}-\mathrm{C}(=\mathrm{O})-\mathrm{N}]$, and others. Binding energies of these bonds are different from each other [24-26] as summarized in Table 1, and the spectra in Figure 1 have to be curve-fitted accordingly to separate out one component from others. The results of curve-fitting are also presented in Figure 1. In the figure, dotted lines indicate the raw $\mathrm{C} 1 \mathrm{~s}$ spectra, narrow solid lines the curve-fitted peaks, and thick lines at the bottom the backgrounds, respectively. In Table 1, each constituent peak is assigned to a proper bond. The changes in the sizes (areas) of the constituent peaks between 'without both electron-irradiation and $\mathrm{Fe}$ ion' and 'with both electron-irradiation and $\mathrm{Fe}$ ion' are tabulated and indicate the possible bond cleavages or the production of the corresponding bonds. The relative sizes of some peaks are increased, while others are decreased.

For one run of experiment, 16 DNA film samples were made identically - among them, 8 samples were 
LEE-unirradiated and having no $\mathrm{Fe}$ ion, and the other 8 samples were LEE-irradiated and having $\mathrm{Fe}$ ion. One standard deviation $(1 \sigma)$ of the average peak-size changes was about 3\%. Therefore, any change less $3 \%$ was considered statistically no meaningful. From Table 1 and Figure 1, we inferred the meaning indicated by the changes in the sizes of the peaks. The 285-eV peak, which is corresponding to $\mathrm{C}-\mathrm{H}$ and $\mathrm{C}-\mathrm{C}$ bonds, is decreased from $45.7 \%$ to $33.5 \%$ in its size. On the other hand, the $286-287 \mathrm{eV}$ peak, which is corresponding to $\mathrm{C}-\mathrm{N}, \mathrm{N}-\mathrm{C}-\mathrm{N}, \mathrm{C}-\mathrm{O}-\mathrm{C}$, and $\mathrm{C}-\mathrm{OH}$ bonds, is increased from $39.9 \%$ to $54.9 \%$. The $288-\mathrm{eV}$ peak corresponding to $\mathrm{N}-\mathrm{C}=\mathrm{O}$ bond and the $289-\mathrm{eV}$ peak corresponding to $\mathrm{N}-\mathrm{C}(=\mathrm{O})-\mathrm{N}$ bond show small changes to draw any conclusion. Most noticeable change is a big increase of 286-287 eV peak. Interestingly, we have noticed the similar increases of 286-287 eV peak when we irradiated thymine and adenine bases with low-energy electron $(5 \mathrm{eV})$ in our separate, unpublished experiments. Therefore, we can conclude that this change is related to the damage of bonds associated with thymine and adenine bases. Also Ptasinska et al [27] noticed the rise of $286-287 \mathrm{eV}$ peak and they concluded that this rise of the signal identifies that a new product is formed as a result of X-ray exposure on DNA sample (without $\mathrm{Fe}$ ion), which contains one of the C-N, N-C-N, C-O-C, C-OH components. Considering that the changes in the peaks sizes are relative, not absolute, the decrease in $285 \mathrm{eV}$ peak could be interpreted in two ways: (i) real decrease associated with $\mathrm{C}-\mathrm{H}$ and $\mathrm{C}-\mathrm{C}$ bonds or (ii) just a relative decrease due to the increase in $286-287 \mathrm{eV}$ peak. To conclude, we need a further study.

We also did the same experiments for (a) the DNA samples with electron irradiation only (i.e., no Fe ion) and (b) the samples with Fe ion only (i.e., no electron irradiation). However, for these samples, the XPS spectra are not very different from those spectra for the DNA sample with no irradiation and no $\mathrm{Fe}$ ion. This observation is consistent with the result which we obtained in the previous gel electrophoresis experiment [17], as further discussed below. Therefore, we did not show and discuss the results for these two cases.

We would like to compare these conclusions with the results we obtained in the previous experiments [17] where we analyzed the damage of DNA using gel electrophoresis technique instead of XPS. When just adding $\mathrm{Fe}^{3+}$ ion to supercoiled DNA (i.e., without LEE irradiation), there was only a slight damage in the range of 0 to $7 \mathrm{mM} \mathrm{Fe}{ }^{3+}$ concentration. In the case when there was only LEE irradiation (i.e., without $\mathrm{Fe}^{3+}$ ion), there were only very little DNA damages; $1.10 \%$ and $1.17 \%$ for $3 \mathrm{eV}$ and $5 \mathrm{eV}$ electron irradiations, respectively. In other words, a single effect of either $\mathrm{Fe}^{3+}$ ion or LEE irradiation did not cause a significant damage. However, when these two components were combined, the DNA damage was increased quite significantly, compared to the sum of DNA damages caused by $\mathrm{Fe}^{3+}$ ion and by LEE irradiation independently. As stated above, this observation is consistent with the present result obtained using XPS analysis. However, in the gel electrophoresis analysis, we could not derive any information about the bond breaks.

\section{CONCLUSION}

We have employed XPS technique to examine the combined effects of LEE irradiation and $\mathrm{Fe}^{3+}$ ion on DNA damage. The C1s spectra were scanned for LEE-irradiated LEE-unirradiated samples. Most noticeable change in C1S spectra is a big increase of 286-287 eV peak. We have noticed the similar increases of 286-287 eV peak when we irradiated thymine and adenine bases with low-energy electron (5 $\mathrm{eV}$ ) in our separate experiments, and therefore, we can conclude that this change is related to the damage of bonds associated with thymine and adenine bases. This observation is also supported by other previous reports. For the samples with LEE irradiation only or with $\mathrm{Fe}$ ion only, no significant changes from pure DNA samples were observed. In other words, a single effect of either $\mathrm{Fe}^{3+}$ ion or LEE irradiation did not cause a significant damage. However, when these two components were combined, the DNA damage was increased quite significantly, compared to the sum of DNA damages caused by $\mathrm{Fe}^{3+}$ ion and by LEE irradiation independently. This observation is consistent with our previous results which was done using gel-electrophoresis technique.

\section{ACKNOWLEDGEMENTS}

This study was supported by research fund of Chungnam National University in 2014.

\section{REFERENCES}

1. Boudaiffa B, Cloutier P, Hunting D, Huels MA, Sanche L. Resonant formation of DNA strand breaks by low-energy( 3 to $20 \mathrm{eV}$ ) electrons. Science. 2000;287:1658-1660.

2. Sanche L. Low energy electron-driven damage in biomolecules. Eur Phys J D. 2005;35:367-390.

3. Huels MA, Parenteau L, Sanche L. Reactive scat- 
tering of $1-5 \mathrm{eV} \mathrm{O}^{-}$in films of tetrahydrofuran. $\mathrm{J}$ Phys Chem B. 2004;108:16303-16312.

4. Barrios R, Skurski P, Simons J. Mechanism for damage to DNA by low-energy electrons. J Phys Chem B. 2002;106:7991-7994.

5. Ptasinska S, Sanche L. On the mechanism of anion desorption from DNA induced by low energy electrons. J Chem Phys. 2006;125:144713.

6. Berdys J, Anusiewics I, Skurski P, Simons J. Damage to model DNA fragments from very low-energy $(<1 \mathrm{eV})$ electrons. J Am Chem Soc. 2004;126:6441.

7. Martin F, Burrow PD, Cai Z, Cloutier P, Hunting D, Sanche L. DNA strand breaks induced by $0-4$ eV electrons: The role of shape resonances. Phys Rev Lett. 2004;93:068101.

8. Lu QB, Sanche L. Condensed-phase effects ob absolute cross sections for dissociative electron attachment to CFCs and FCFCs adsorbed on Kr. J Chem Phys. 2003;119:2658-2662.

9. Lu QB, Sanche L. Enhancement in dissociative electron attachment to $\mathrm{CF}_{4}$, chlorofluorocarbons and hydrofluorocarbons adsorbed on $\mathrm{H}_{2} \mathrm{O}$ ice. J Chem Phys. 2004;120:2434-2438.

10. Christophorou LG, McCorkle DL, Christodoulides AA. Electron-Molecule Interactions and Their Applications. New York; Academic Press. 1984.

11. Chutjian A, Garscadden A, Wadehra JM. Electron attachment to molecules at low electron energies. Phys Rep. 1996;264:393-470.

12. Ying ZC, Ho WJ. Photodissociation of adsorbed $\mathrm{MO}(\mathrm{CO})_{6}$ induced by direct photoexcitation and hot-electro attachment. 2. Physical mechanisms. J Chem Phys. 1991;94:5701-5714.

13. Sanche L. Nanoscopic aspects of electronic aging in dielectrics. IEEE Trans Dielectr Electr Insul. 1997;4:507-543.

14. Lu QB, Sanche L. Effects of cosmic rays on atmospheric chlorofluorocarbon dissociation and ozone depletion. Phys Rev Lett. 2001;87:078501.

15. Park YS, Cho H, Parenteau L, Bass AD, Sanche L. Cross sections for electron trapping by DNA and its component subunits I: condensed tetrahydrofuran deposited on Kr. J Chem Phys. 2006;125: 074714.

16. Voet D, Voet JG, Pratt CW. Fundamentals of Biochemistry. New York; Wiley. 1999.

17. Park Y, Noh H-A, Cho H. Effect of low-energy electron irradiation on DNA damage by $\mathrm{Fe}^{3+}$ ion. Radiation Res. 2012;177;775-780.

18. Aruoma OI, Halliwell B, Gajewski E, Dizdaroglu M. Copper-ion-dependent damage to the bases in DNA in the presence of hydrogen-peroxide. Biochem J. 1991;273:601-604.

19. Keyer K, Imlay JA. Superoxide accelerates DNA damage by elevating free-iron levels. Proc Natl Acad Sci USA. 1996;93:13635-13640.

20. Kasprzak KS. Oxidative DNA and protein damage in metal-induced toxicity and carcinogenesis. Free Radic Biol Med. 2002;32: 958-967.

21. Gao YG, Sriram M, Wang AH. Crystallographic studies of metal-ion DNA interactions-different binding modes of cobalt(III), copper(II) and barium(II) to N-7 of guanines in Z-DNA and a drug-DNA complex. Nucleic Acid Res. 1993;21: 4093-4101.

22. Lloyd DR, Phillips DH. Oxidative DNA damage mediated by copper(III), iron(II) and nickel(II) Fenton reactions. Mutation Res. 1999;424:23-36.

23. Garcia J, Subias G, Cuartero V, Herrero-Martin J. On the correlation between the X-ray absorption chemical shift and the formal valence state in the mixed-valence manganites. J Synchrotron Rad. 2010;17:386-392.

24. May CJ, Canavan HE, Castner DG. Quantitative X-ray Photoelectron Spectroscopy and Time-ofFlight Secondary Ion Mass Spectrometry Characterization of the Components in DNA. Anal Chem. 2004;76:1114.

25. Peeling J, Hruska FE, McIntyre NS. ESCA spectra and molecular charge distributions for some pyrimidine and purine bases. Can J Chem. 1978; 56:1555.

26. Furukawa M, Fujisawa H, Katano S, Ogawawara H, Kim Y, Komeda T, Nilsson A, Kawai M. Geometrical characterization of pyrimidine base molecules adsorbed on $\mathrm{Cu}(110)$ surfaces: XPS and NEXAFS studies. Surf Sci. 2003;532-535:261266.

27. Ptasinska S, Stypczynska A, Nixon T, Mason N J, Klyachko D V, Sanche L. X-ray induced damage in DNA monitored by X-ray photoelectron spectroscopy. J Chem Phys. 2008;129:065102. 